\title{
Thema: Naar een beter begrip van private equity
}

\section{Arnoud Boot}

SAMENVATTING Zelden domineert een onderwerp zozeer het maatschappelijke debat: zijn private equity en activistische aandeelhouders een zegen of een probleem? Veel Nederlandse beursgenoteerde ondernemingen, van ABN AMRO, (voormalige) VNU tot Stork en Ahold, voelen de druk van private equity investors en aandeelhoudersactivisme in het algemeen. Dit themanummer van het MAB is geheel gewijd aan dit onderwerp. Hoewel in de populaire media veelal centraal staat of private equity en aandeelhoudersactivisme maatschappelijk gewenst zijn (en wat dit bijvoorbeeld betekent voor de factor arbeid), wordt in dit themanummer primair ingegaan op het begrijpen van de rol die wordt gespeeld door private-equityinvesteerders. Juist dit begrip is cruciaal voor de verdere verdieping van de maatschappelijke discussie.

\section{Inleiding ${ }^{1}$}

Het leven van de grotere Nederlandse beursvennootschappen was tot voor kort eenvoudig: het management en de raad van commissarissen maakten de dienst uit. Ze moesten het wel heel bont maken voordat er rumoer ontstond. Aandeelhouders moesten vooral niet te moeilijk doen. Vanuit deze gemoedelijke praktijk is het niet verrassend dat de recente ontwikkelingen op het gebied van private equity en aandeelhoudersactivisme enigszins zwaar op de maag gevallen zijn; niet alleen bij bestuurlijk

Prof. dr Arnoud W.A. Boot is hoogleraar Ondernemingsfinanciering en Financiële Markten aan de Universiteit van Amsterdam en directeur van het interfacultaire Amsterdam Center for Law \& Economics. Tevens is hij director van het Amsterdam Center for Corporate Finance (ACCF) en adviseur en commissaris bij verschillende bedrijven en instellingen.
Nederland maar met name ook bij de politiek en de vakbeweging.

Aandeelhoudersactivisme is iets nieuws voor Nederland. Nederlandse bedrijven, zoals ABN AMRO, (voormalige) VNU, CSM, TNT, Ahold, Stork en zelfs DSM, voelen allemaal de druk van private equity investors. Deze snel zichzelf mobiliserende grootaandeelhouders hebben in korte tijd veel macht veroverd. Voor Nederland is het 'probleem' van activistische aandeelhouders mogelijk extra groot omdat - in tegenstelling tot andere continentaal Europese landen - Nederlandse ondernemingen een relatief open eigendomsstructuur kennen die ervoor zorgt dat ondernemingen nogal gevoelig zijn voor activistische aandeelhouders (Boot, 2007a).

Ondernemingen voelen zich in het nauw gedreven. Ze worden niet alleen met deze wederopstanding van aandeelhouders geconfronteerd, maar tegelijkertijd met allerlei extra regels en eisen die voortkomen uit nieuwe wet- en regelgeving. Zoals de Amerikaanse Sarbanes Oxley Act (SOx), aangenomen in de slipstream van de schandalen van afgelopen jaren. Door alle regels die hierin en in de Europese varianten daarop voorkomen (vergelijk ook de code-Tabaksblat; CCG, 2003) wordt de speelruimte van ondernemingen - beursgenoteerde vennootschappen wel te verstaan beperkt. Zware verantwoordingseisen over het verleden lijken deze ondernemingen van het 'ondernemen' af te houden, en dat terwijl je als ondernemer vooral met de toekomst bezig wilt zijn. In de Amerikaanse context heeft de introductie van SOx al geleid tot de instelling van commissies die met enige zorg spreken over de afnemende concurrentiekracht van Amerikaanse financiële markten (zie Zingales, 2007).

Dit is ook een van de redenen voor dit themanummer van het MAB. We moeten het functioneren en bestaan van private-equitypartijen beter begrijpen. Vanuit dit 
grotere begrip zijn dan mogelijk beleidsaanpassingen mogelijk. Hoewel in de populaire media veelal centraal staat of private equity en aandeelhoudersactivisme maatschappelijk gewenst zijn (en wat dit bijvoorbeeld betekent voor de factor arbeid ${ }^{2}$ ), wordt in dit themanummer primair ingegaan op het begrijpen van de rol die wordt gespeeld door privateequityinvesteerders. Juist dit begrip is cruciaal voor de verdere verdieping van de maatschappelijke discussie. Hiermee kan ook worden voorkomen dat beleid verzandt in incidentenpolitiek, iets wat bijvoorbeeld de commissie-Frijns met haar laatste rapport van mei j.l. is verweten (MCCG, 2007).

\section{Private-equityrevolutie?}

De private-equityrevolutie duidt op een mogelijke herschikking van ondernemingen tussen beursnotering en niet-beursnotering. ${ }^{3}$ Private-equitypartijen kunnen ondernemingen van de beurs halen en daarmee de mogelijk excessieve wet- en regelgeving voor beursgenoteerde ondernemingen vermijden. Als zij namelijk de anonieme en kleine aandeelhouders uitkopen, vervalt de noodzaak van de op de bescherming van anonieme aandeelhouders gerichte wet- en regelgeving. De genoemde Sarbanes Oxleywetgeving in de VS en de code-Tabaksblat zijn terecht in principe niet van toepassing op niet-beursgenoteerde ondernemingen. ${ }^{4}$

De betrokkenheid van private equity kan echter ook leiden tot actieve grootaandeelhouders bij een continuering van de beursnotering. In dat geval wordt vaak gesproken over hedgefondsen die mogelijk meer speculatief zijn ingesteld. Hedgefondsen onderscheiden van private equity is in mijn ogen niet goed mogelijk. In beide gevallen worden aandelenposities ingenomen en hoewel de term private equity suggereert dat dit in niet-beursgenoteerde ondernemingen is, zijn private-equityinvesteerders wel degelijk ook actief in beursgenoteerde ondernemingen. Dus het populaire onderscheid tussen kwalijke meer kortetermijngeoriënteerde activiteiten van hedgefondsen in beursvennootschappen en het meer acceptabele gedrag van private-equityfondsen is nogal gekunsteld. Hoe dan ook, de betrokkenheid van private equity (of hedgefondsen) bij beursgenoteerde ondernemingen zorgt voor een grotere concentratie onder aandeelhouders. Hiermee lost private equity het probleem op dat bij een wijdverspreid aandelenbezit aandeelhouders door de mate van spreiding een te klein eigen belang hebben om de onderneming voldoende in de gaten te kunnen houden. Overigens moeten we private equity en de 'wederopstanding' van grootaandeelhouders niet zien als iets totaal nieuws. Integendeel, directe invloed via grootaandeelhouders is altijd van groot belang geweest. Hoogstens zouden we kunnen zeggen dat er in de praktijk een te groot vertrouwen is geweest in de financiële markten. Vooral is veronachtzaamd dat door de spreiding van eigendom over een groot aantal (vaak anonieme) aandeelhouders een groot machtsvacuüm is ontstaan. ${ }^{5}$ Dit vacuüm wordt door de private-equityrevolutie en de 'wederopstanding' van grootaandeelhouders opgevuld. ${ }^{6}$

\section{Grote macht private equity in Nederland}

In mijn column in het MAB van juni 2006 (Boot, 2006) gaf ik aan dat er voor ondernemingen niet veel verlichting is te verwachten, vanwege:

- de legitieme zorgen over het beschermen van anonieme aandeelhouders in de openbare kapitaalmarkten; en

- de ontmanteling van juridische beschermingsconstructies.

Doordat het principe one-share-one-vote op Europees niveau een zwaar gewicht krijgt, en juridische beschermingsconstructies hiermee veelal in strijd zijn, is juist Nederland buitengewoon gevoelig voor private-equitypartijen en voor de mobilisatie van grootaandeelhouders. Dit geldt voor Nederland zwaarder dan voor het buitenland. Continentaal Europa, zowel de Scandinavische landen, Duitsland als Latijns Europa, kent cross holdings en andere vormen van economische bescherming via specifieke eigendomsverhoudingen, bijvoorbeeld piramidestructuren. Nederland daarentegen heeft een veel transparantere eigendomsstructuur waarbij ondernemingen veelal direct in handen zijn van (eind)beleggers.

Ook wees ik op verschillen met de Verenigde Staten, en met name dat de ondernemingsleiding van een Amerikaans beursfonds vaak nadrukkelijker is beschermd tegen aandeelhouders. Zo kunnen bestuurders en/of commissarissen niet zomaar worden weggestuurd. De invloed van aandeelhouders is meer achteraf. Achterblijvende ondernemingen in de Verenigde Staten zullen vroeg of laat worden overgenomen, dit is de zogenaamde 'market for control'.

Gesteld kan dus worden dat de wijzigingen in corporate governance aandeelhouders in Nederland een aanzienlijke zeggenschap hebben gegeven over ondernemingsbesluiten. Een voorbeeld is de eis in de code-Tabaksblat dat materiële beslissingen worden voorgelegd aan de aandeelhouders. Een dergelijke 
inspraak vooraf is veel minder dominant in de Amerikaanse praktijk die veeleer controlerend achteraf is. Voor Nederlandse beursgenoteerde ondernemingen zou dit kunnen betekenen dat het mandaat voor de ondernemingsleiding is aangetast. $\mathrm{Zij}$ wordt in zekere zin zowel vooraf als achteraf aan banden gelegd. Hoewel dit wat extreem is geformuleerd, is er wel degelijk een zorg. Als het inderdaad aan een mandaat ontbreekt dan veroorzaakt dit mogelijk een grote aanslag op het ondernemende karakter van de onderneming.

\section{Nuancering bij Nederlandse ontwikkelingen}

Een belangrijke nuancering bij de vermeende grote macht van private equity is dat veel Nederlandse bedrijven die in het nieuws kwamen door een opstand onder aandeelhouders dit vooral aan zichzelf te wijten hadden.

- VNU presteerde onvoldoende - was er niet in geslaagd een aantal overnames tot een goed einde te brengen - en kon dan ook niet verwachten dat aandeelhouders zouden instemmen met (weer) een grote overname. Een vlucht naar voren is zelden optimaal. De snel gemobiliseerde aandeelhouders voorkwamen dit. Dit is positief.

- Ook in het geval van ABN AMRO ging er een periode van zeven jaren van niet waargemaakte beloftes vooraf aan de brief van TCI van februari jl. die aandrong op opsplitsing. En zoals ik elders heb verwoord (zie NRC, 5 april 2007), was het veeleer de paniekreactie van $A B N A M R O$ en het niet ingrijpen van haar raad van commissarissen die ABN AMRO in acute problemen bracht.

Wel is het zo dat door de macht van de aandeelhouders ondernemingen sneller in een verdomhoekje terecht komen. ABN AMRO is een mooi voorbeeld. Als aangeschoten wild gaan ze door het leven en ze kunnen niets meer goed doen. Dit is een duidelijke verharding van het speelveld. Het is een beetje alles of niets geworden. Je bent een held of je bent afgebrand. Het lijkt wel iets op een voetbaltrainer van een topploeg. Je doet het goed en iedereen loopt weg met je, maar o wee als er iets misgaat, dan laten ze je vallen als een baksteen ${ }^{7}$. Wat niet helpt is dat de financiële markt vaak momentum is gedreven. Meevallers en tegenvallers worden dan nog eens extra uitvergroot.

Is het werkelijk zo dat de toenemende regelgeving leidt tot minder flexibiliteit en haaks staat op ondernemerschap? Dit is waarschijnlijk het geval, maar een nauwkeurige afbakening van regelgeving, en de wenselijkheid ervan, is nodig. Als het gaat om de financiële markt, dan hebben we het over regels die bijvoorbeeld gelijke informatievoorziening aan alle partijen in de markt bewaken; regels met betrekking tot handel met voorkennis, enzovoort. Dit zijn gewenningsregels. Deze regels zullen uiteindelijk niet echt belemmerend zijn.

Overgangsproblemen zijn er echter wel degelijk. Hoe te communiceren bijvoorbeeld naar aandeelhouders? Kan een onderneming in gesprek treden met privateequitypartijen? En hoe wordt dan een gelijke informatievoorziening bewaakt aan alle andere aandeelhouders? Dit is lastig, maar kan met bepaalde gedragsregels en procedures in goede banen worden geleid (zie ook enige van de voorstellen in MCCG, 2007).

Minder gemakkelijk ligt het met corporate governance regels die meer intern zijn gericht (ondernemingsrecht, zie ook Tabaksblat-code). Hier zit een groter probleem. Het gaat hier over bijvoorbeeld boxticking in plaats van sturing op basis van principes. Regels die direct ingrijpen op het ondernemingsbestuur, bijvoorbeeld maxima stellen aan het aantal commissariaten per persoon, of een verbod op het opnemen van voormalige bestuurders in de RvC. Deze regels zijn lang niet altijd optimaal. Een vraag is ook of de aandeelhoudersvergadering (AvA) hier niet over moet gaan. Ook speelt het genoemde gebrek aan mandaat. Hoe dit op te lossen is verre van vanzelfsprekend. Hier zit dus wel degelijk een probleem. De vraag is of we wel op de goede weg zijn. ${ }^{8}$

\section{Bijdragen in dit themanummer}

Bovenstaande overwegingen geven enige nuancering bij de rol van private-equitypartijen en activistische aandeelhouders in het bijzonder. Toch blijft de analyse tamelijk algemeen. Cruciaal is om private-equitypartijen beter te begrijpen, en dat is waaraan de bijdragen in deze special invulling trachten te geven. In een zestal bijdragen wordt een nader inzicht gegeven van de rol van private-equitypartijen vanuit een drietal gezichtspunten, namelijk vanuit

- de invloed op de performance van de onderneming waarin ze investeren;

- de beleggers zelf (dus de private-equityinvesteerders/ beleggers); en

- de toezichthouder en wet- en regelgever.

In de eerste bijdrage van Han Smit en Ward van den Berg staat de vraag centraal naar en het aanbod van private equity, met name bezien vanuit het perspectief van private-equityinvesteerders/beleggers. Zij 
beschrijven een golfpatroon in investeringsvolumes die zorgen voor een nogal dynamische markt met sterk wisselende rendementen voor beleggers.

In de tweede bijdrage analyseert Anjolein Schmeits belangenconflicten die kunnen ontstaan tussen de bij transacties betrokken partijen. Het gaat om geld, en veel geld, en dat kan aanzetten tot het gebruiken van inside-informatie en mogelijk het samenspannen van management en private-equitypartijen ten koste van (kleine) derde aandeelhouders. Ook problemen verbonden aan (mogelijk excessieve) financiering met vreemd vermogen en een mogelijke marktverstorende samenwerking tussen private-equitypartijen onderling worden besproken.

In de derde, vierde en vijfde bijdrage staan respectievelijk Groot Brittannië, de VS en België centraal. Jana Fidrmuc, Peter Roosenboom en Dick van Dijk (FRD) vergelijken in hun bijdrage hoe in Groot Brittannië het van de beurs halen van ondernemingen door private-equitypartijen zich vergelijkt tot dezelfde transacties maar dan geïnitieerd door het management (management buy-outs, MBO's). Het blijkt dat sprake is van verschillende soorten ondernemingen, en dat private equity in vergelijking tot MBO's eerder wordt gekozen door ondernemingen die weliswaar grotere voordelen lijken te hebben van een beursnotering maar krap bij kas zitten. Een mogelijke interpretatie is dat de private-equitypartijen er bij worden geroepen als de complexiteit groter is.

Armin Schwienbacher concentreert zich in de vierde bijdrage op het investeringsgedrag van Amerikaanse institutionele beleggers. Hij laat met name zien welke Amerikaanse institutionele beleggers genegen zijn in buitenlandse private-equityfondsen te investeren. In de vijfde bijdrage bekijken Lotte Goossens, Sophie Manigart en Miguel Meuleman hoe 288 Belgische ondernemingen zich na een buy-out verder hebben ontwikkeld. Zij gaan met name in op de vraag wat de invloed is van het al dan niet aanwezig zijn van een private-equityinvesteerder bij de buy-out voor veranderingen in efficiëntie. Dit is overigens een ingewikkeld causaliteitsvraagstuk. Als private-equityinvesteerders alleen aanwezig zijn bij de meest complexe deals, zoals gesuggereerd in de derde bijdrage van FRD, dan zou in het geval van betrokkenheid van private-equityinvesteerders de efficiëntiestijging mogelijk lager kunnen zijn, zonder dat dit ook maar iets negatiefs (of positiefs) zegt over de toegevoegde waarde van deze investeerders.

In het laatste - zesde - artikel gaan Joseph McCahery en Erik Vermeulen in op de regulering van private equity. Zij concluderen dat grote onduidelijkheid en meningsverschillen bestaan over de noodzaak van nieuwe regulering voor deze beleggingscategorie, en dat verder (economisch) onderzoek noodzakelijk is. Ook gaan zij in op verschillen tussen private equity en hedgefondsen.

\section{Slot}

$\mathrm{Al}$ met al bieden deze zes bijdragen vele fundamentele inzichten die het debat over private equity en aandeelhoudersactivisme in Nederland verder kunnen helpen. Zoals aangegeven staan in deze bijdragen, naast het reguleringsvraagstuk, centraal het beter begrijpen van private-equityinvesteerders zelf en de invloed die ze hebben op de performance van ondernemingen waarin wordt geïnvesteerd. De discussie over machtsverhoudingen in ondernemingsland, inclusief de rol van de raad van commissarissen en de factor arbeid (werknemersbelangen), vallen buiten de reikwijdte van deze special. Voor enige gedachten hierover zie Boot (2007b).

\section{Literatuur}

Berle, A.A. en G.C. Means (1936), The Modern Corporation and Private Property, MacMillan, New York.

Boot, A.W.A. (2006), Hoe verder in ondernemingsland. Wie heeft er nog de macht?, Maandblad voor Accountancy en Bedrijfseconomie, jg. 80, no. 6 (juni), pp. 272, 273

Boot, A.W.A. (2007a), Private equity: actie nodig ..., Bank- en Effectenbedrijf, maart, pp. 36-41.

Boot, A.W.A. (2007b), Activistische aandeelhouders een zegen? Maandblad voor Accountancy en Bedrijfseconomie, vol. 81, no. 6 (juni), pp. 236-238.

Boot, A.W.A., R. Gopalan en A.V. Thakor (2006), The enterpreneur's choice between private and public ownership, Journal of Finance, vol. 61, no. 2 , (april), pp. 803-836

Boot, A.W.A., R. Gopalan en A.V. Thakor (2007), Market liquidity, investor participation and managerial autonomy: why do firms go private, te verschijnen, Journal of Finance, zie www.acle.nl.

Boot, A.W.A., en P. Wallage (2006), Formele versus materiële naleving van de code Tabaksblat, Maandblad voor Accountancy en Bedrijfseconomie, vol. 80, nummer 5 (mei), pp. 206-215.

CCG - Commissie Corporate Governance (2003), De Nederlandse corporate governance code. Beginselen van deugdelijk ondernemingsbestuur en best practice bepalingen, 9 december 2003 (Code Tabaksblat).

MCCG - Monitoring Commissie Corporate Governance (2007), Advies over verhouding tussen vennootschap en aandeelhouders en over het toepassingsbereik van de Code, mei.

Shleifer, A., en R. Vishny (1997), A survey of corporate governance, Journal of Finance, 52 (2), pp. 737-783.

Zingales, L. (2007), Is the US capital market losing its competitive edge? te verschijnen, Journal of Economic Perspectives. 


\section{Noten}

1 Dit artikel bouwt voort op de karakterisering van ontwikkelingen zoals geschetst in Boot (2007a).

2 Argumentatie hoeft overigens niet ideologisch bepaald te zijn om de noodzaak van aandeelhoudersinvloed te kunnen rechtvaardigen. In de Angelsaksische literatuur wordt dit meestal gekoppeld aan de opmerking dat aandeelhouders nu eenmaal de eigenaar zijn van de onderneming en dus het voor het zeggen (moeten) hebben. Ik beschouw dit onnodig polariserend; een één-dags aandeelhouder is meer 'eigenaar' dan een werknemer die er al 20 jaar werkt? Het is veel meer voor de hand liggend te verwijzen naar de grotere wetgevende en contractuele bescherming van werknemers en crediteuren in vergelijking tot aandeelhouders; zie de gedetailleerde contracten (arbeidscontract respectievelijk leningovereenkomst) en extensieve wetgeving (arbeidsrecht en crediteurenbescherming in de faillissementswet) vergeleken met de 'restpost' positie van aandeelhouders. Aandeelhouders als 'residual claimant' verdienen dus invloed binnen het corporate-governancekader ter compensatie van de bescheiden contractuele en wetgevende bescherming. In andere woorden: het contract (inclusief wetgevende bescherming) van de aandeelhouders is veel minder volledig dan dat van werknemers en crediteuren.

3 Deze herschikking zal de vraag oproepen voor welke ondernemingen en in welk stadium van hun ontwikkeling een beursnotering optimaal is (zie Boot et. al., 2006, 2007). Of er minder bedrijven in de toekomst op de beurs genoteerd zullen zijn, valt niet zeggen. Wat ik wel verwacht is dat het hebben van wel of geen beursnotering een meer dynamisch proces zal worden. Ondernemingen zullen vaker de beurs betreden en weer verlaten, en later mogelijk weer betreden, afhankelijk van de specifieke omstandigheden en levensfase waarin de onderneming zich bevindt.

4 Algemene eisen, zoals een verplichting tot een controle op de jaarrekening, vervallen niet. Deze zijn gekoppeld aan de grootte van de onderneming en dienen onder meer ter bescherming van werknemers en crediteuren.

5 Overigens heeft de wetenschappelijke literatuur wel degelijk veel aandacht besteed aan dit machtsvacuüm en dat al voor een hele lange periode (zie Berle en Means, 1936; en Shleifer en Vishny, 1997).

6 Waar codes en regelgeving te knellend worden, zullen private-equitypartijen via MBO's en andere go-privatetransacties de onderneming van de beurs halen. Maar zoals blijkt uit de analyse in de hoofdtekst is het zeker niet zo dat het bestaansrecht van private-equitypartijen voortkomt uit de mogelijk knellende code en regelgeving. Private equity en de mobilisatie van grootaandeelhouders in het algemeen zijn complementaire governancemechanismen.

7 De analogie is nog sterker. Voetbaltrainers kunnen het succes veelal nooit lang volhouden. Vroeg of laat (en tegenwoordig steeds vroeger) zijn ze opgebrand. Het verbaast dan ook niet dat de 'omlooptijd' van bestuurders korter is geworden.

8 Zie ook Boot en Wallage (2006). Zij wijzen op de risico's die verbonden zijn aan de toenemende regeloriëntatie ('box ticking') en beargumenteren dat een op vertrouwen gebaseerde integriteitstrategie vaak voordelen heeft boven een op wantrouwen gebaseerde regelstrategie. 